\title{
Correlations Between Heparinated Blood Glucose Determined with Automatic Analyzers and the Severity of the Acute Coronary Disease
}

\author{
MARIA CRISTINA VLADEANUㄴ, IRIS BARARU BOJAN ${ }^{1 *}$, IULIANA ARDELEANU², ANDREI BOJ AN ${ }^{3}$, DAN ILIESCU², \\ PAUL DAN SIRBU4*, CARMEN ELENA PLESOIANU², TEODOR VASILCU², DRAGOS MARCU², MANUELA CIOCOIU1*, \\ CODRUTA BADESCU ${ }^{2}$, MAGDA BADESCU ${ }^{1}$, OANA VIOLA BADULESCU ${ }^{1}$ \\ ${ }^{1}$ Grigore T. Popa University of Medicine and Pharmacy, Department of Pathophysiology, 16 Universitatii Str., 700115, lasi, \\ Romania \\ ${ }^{2}$ Grigore T. Popa University of Medicine and Pharmacy, Department of Medical Sciences, 16 Universitatii Str., 700115, Iasi, \\ Romania \\ ${ }^{3}$ Grigore T. Popa University of Medicine and Pharmacy, Department of Surgical Sciences, 16 Universitatii Str., 700115, Iasi, \\ Romania \\ ${ }^{4}$ Grigore T. Popa University of Medicine and Pharmacy, Department of Orthopedics and Traumatology, 16 Universitatii Str., \\ 700115, Iasi, Romania
}

\begin{abstract}
Diabetes is one of the most important cardiovascular risk factors. Hyperglycemia leads to several metabolic alterations, thus creating conditions for a poor cardiovascular outcome. Our study phocussed on the prevalence of glucidic metabolism alterations in the acute coronary disease, as well as the association between hyperglycemia, diabetes and severe coronary lesions. We performed a study on 58 patients with acute coronary artery disease, divided in two groups, unstable angina and acute myocardial infarction and we evaluated the severity of the disease based on the angiographical results: no vessel disease (no significant lesions), one-vessel disease (one arterial stenosis/occlusion), two-vessel disease (two stenotic coronary arteries) and three-vessel disease (lesions of all three coronary arteries). Blood samples were collected in heparinated tubes and rapidly transferred to the laboratory for analysis, using automated glucose analyzers, in order to preventerrors due to glycolysis. More than half of the patients were diabetic and glycemic values were significantly higher in patients with myocardial infarction (126.67 vs $163.64 \mathrm{mg} / \mathrm{dL}$ ). The prevalence of diabetes was significantly higher among the three vessel disease patients, both with unstable angina (38.9\%; $p=0.037$ ) and with myocardial infarction (35.1\%; $p=0.345$ ). In conclusion, diabetes and hyperglycemia create the setting for acute coronary disease, especially with lesions of all the three coronary arteries.
\end{abstract}

Keywords acute myocardial infarction, unstable angina, coronary artery disease, hyperglycemia, diabetes

Coronary artery disease is the most common complication of diabetes. Patients with T2DM display a predisposition for accelerated atherosclerosis, the studies comparing the prevalence of coronary artery disease in diabetic and non-diabetic patients have shown a threefold higher incidence of atherosclerosis and a tw ofold higher cardiovascular risk when diabetes is associated [1,2]. Diabetic hearts have accentuated cellular damage and severly reduced cellular reserve and are more exposed to future cardiac events [3,4]. The hyperglycemia associated with diabetes can lead to modification of macromolecules, for example, by forming advance glication end products (AGE) $[5,6]$. By binding surface receptors such as RAGE (receptors for AGE), these AGE-modified proteins can augment the production of proinflammatory cytokines and other inflammatory pathways in vascular endothelial cells. Beyond the hyperglycemia, the diabetic state promotes oxidative stress mediated by reactive oxygen species and carbonyl groups [7]. The toxicity of hyperglycemia over the coronary arteries via metabolic and oxidative mediators, as well as metabolism alterations, is an emerging subject for cardiovascular studies [8]. Our study phocusses on the prevalence of glucidic metabolism alterations in the acute coronary disease, as well as the association between hyperglycemia, diabetes and severe coronary lesions.

\section{Experimental part}

Our analysis was performed on 58 patients with acute coronary artery disease, who performed coronary angiography. Patients were divided into two groups, unstable angina (30 patients) and acute myocardial infarction (28 patients) and we evaluated the severity of the disease based on the angiographical results: no vessel disease (no significant lesions), one-vessel disease (one arterial stenosis/occlusion), two-vessel disease (two stenotic coronary arteries) and three-vessel disease (lesions of all three coronary arteries).

A thorough anamnesis provided us with the presence or absence of diabetes history. We collected blood samples from each patientand determined the level of glucose from heparinated blood, in the first two hours, using blood glucose analyzers and a glucose assay kit.

We used SPSS version 18 to perform the statistical analysis. ANOVA test was done in order to analyze the dispersion of the dependent variable: intra and intergroup. When assessing the significant difference betw een two or more groups, we used for the quantitative variables: the tstudent test and the $\mathrm{F}$ test (ANOVA). To compare clinical and laboratory biochemical and physiological parameters in relation to the studied SNPs and nutritional status, the Kruskal-Wallis and Pearson correlation coefficient were done. Statistical significance was considered to be $p=0.05$

\section{Results and discussions}

The anamnesis revealed that $60 \%$ of the patients with unstable angina and $60.7 \%$ of the patients with myocardial infarction were diabetic (fig.1).

How ever, glycemic values were significantly higher in patients with myocardial infarction (126.67 vs $163.64 \mathrm{mg} /$

\footnotetext{
* email: iris_bararu@yahoo.com; pdsirbu@yahoo.com; mciocoiu2003@yahoo
} 


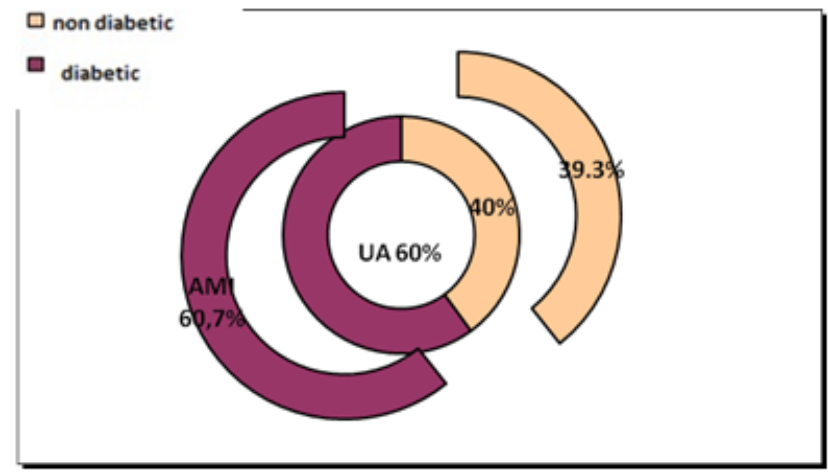

Fig.1. Prevalence of diabetes in the two groups: unstable angina (UA) and acute myocardial infarction (AMI)

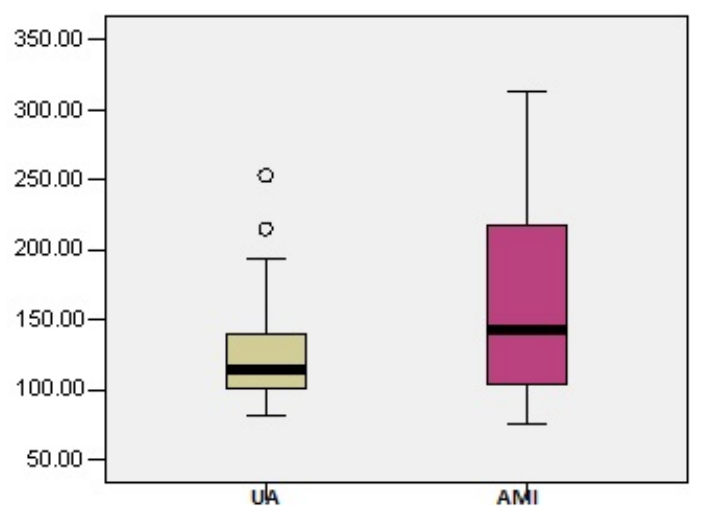

Fig.2. Mean glycemic values ( $\mathrm{mg} / \mathrm{dL}$ ) for unstable angina (UA) and acute myocardial infarction (AMI)

\begin{tabular}{|c|c|c|c|}
\hline $\begin{array}{c}\text { Risk } \\
\text { Factors exposure }\end{array}$ & $\begin{array}{c}\text { AMI group } \\
\text { mean } \pm \text { SD }\end{array}$ & $\begin{array}{c}\text { UA group } \\
\text { mean } \pm \text { SD }\end{array}$ & p \\
\hline Diabetes & $204.00 \pm 59.81$ & $146.22 \pm 39.47$ & $\mathbf{0 . 0 0 2}$ \\
\hline Dyslipidemia & $172.84 \pm 67.99$ & $129.92 \pm 40.02$ & $\mathbf{0 . 0 0 7}$ \\
\hline Obesity & $173.58 \pm 64.59$ & $129.59 \pm 41.48$ & $\mathbf{0 . 0 2 2}$ \\
\hline Smoking & $157.93 \pm 64.54$ & $124.07 \pm 35.95$ & 0.098 \\
\hline
\end{tabular}

Table 1

MEAN GLYCEMIC VALUES IN EACH GOUP, ACCORDING TO THE RISK FACTORS EXPOSURE
$\mathrm{dL}$ ). Individual values ranged between 76 and $313 \mathrm{mg} / \mathrm{dL}$, with $63.8 \%$ over the upper limit ( $<110 \mathrm{mg} / \mathrm{dL}$ ) (fig.2). This shows an important inbalance of the glucidic metabolism in the acute coronary disease, especially associated with acute myocardial infarction.

Glycemic values analysis according to the risk factors exposure revealed higher mean values in the acute myocardial infaction group (table 1).

Our patients were mainly one-vessel diseased $(O C)$ (41.4\%), but alltogether, two-vessel (2C) and three-vessel (3C) diseased patients represented $57 \%$ of the total subjects inlcuded (fig.3).



Fig.3. Coronary status (severity of the coronary artery disease) distribution

The prevalence of diabetes was significantly higher among the three vessel disease patients, both with unstable angina (38.9\%; $p=0.037$ ) and with myocardial infarction (35.1\%; $p=0.345)$ (fig.4).

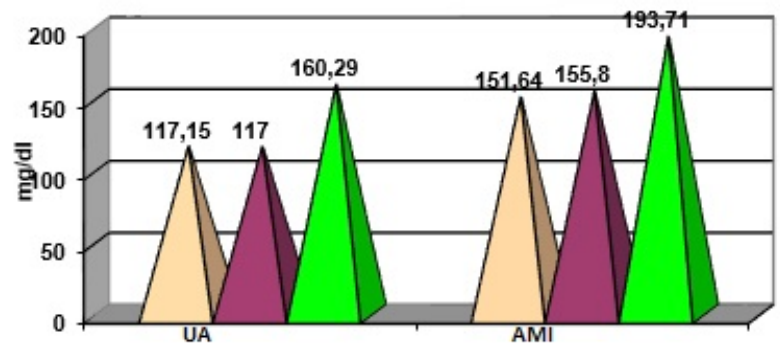

Fig.4. Mean glycemic values according to the study groups, unstable angina (UA) and acute myocardial infarction (AMI) and the severity of the coronary artery disease
Although there is no statistical difference between the two groups, it is clear that diabetes mellitus is a predisposing factor for the acute coronary disease, regardless of its clinical form, since more than half of our patients were diabetic. But what is even more important is that most diabetic patients were three vessel diseased, an argument for the association between diabetes and more severe coronary lesions. Our results are similar to those of other previous studies. The FREEDOM trial, probably the biggest study evaluating diabetic patients with multivessel disease, osteoporosis and increased tendency to multiple fractures, at any level of the bone system, pointed out that most patients had very extensive disease, requiring surgical treatment, which had better results than interventional treatment [9-11].

We paid a special attention to the determination of blood glycemia. It has been long debated whether it is better to use sodium fluoride or heparin in order to preserve the glucose in blood. It is said that the rate of decline in blood glucose is similar in the first hour after taking the blood sample, regardless of the preservation technique we use. The difference appears after the first hour, when glucose in heparinated blood continues to decrease, while fluoride samples remain stable for almost 3 days [12]. Our samples were processed in maxim $2 \mathrm{~h}$, with rapid centrifugation, so we believe the errors due to technique are minimal, although the blood was collected in tubes with heparin, as it is most commonly done. Since we did not preserve the sample too long, there was no need for sodium fluoride, which is very useful when stabilisation of the sample is needed, due to a delay in processing. The issue behind this discussion is the consumption of glucose by the glycolytic enzymes contained by white and red blood cells, leadind to a decrease of glucose by $5 \%$ per hour, sometimes claimimg even $40 \%$ after three hours, so research shows that sodium fluoride reduces this process, but makes it impossible to determin sodium and uris acid from the same sample $[13,14]$.

Most hyperglycaemic patients were three vessel diseased, with myocardial infarction. There is also the 
discussion of stress hyperglycemia, which leads to an increase in mortality, as it has been previously demonstrated by Marfella et al., who raised the hypothesis that myocardial infarction associated with hyperglicemia is characterised by a high inflammatory and immune response, leading to unfavourable cardiac outcomes [13]. This has also been sustained by a systematic review of Deedwania P. et al., linking hypergycemia to adverse cardiac outcomes in patients with acute coronary syndrome $[13,15]$.

\section{Conclusions}

Our study further emphasises the association between diabetes and hyperglycemia in acute coronary syndromes, pointing out the important correlation not only with developping the disease, but also with severe coronary lesions.

\section{References}

1.M. LISAK, V. DEMARIN, Z. TRKANJEC, V. BASIC-KES, Hypertriglyceridemia as a possible independent risk factor for stroke, Acta Clinica Croatica, vol. 52, no.4, pp.458-463, 2013.

2.Y. IKEDA, M. HANDA, K. KAWANO et al., The Role of Von Willebrand Factor and Fibrinogen in Platelet Aggregation under varying Sheer Stress, The Journal of Clinical Investigation, vol. 87, no.4, pp.1234$1240,1991$.

3.G.E. GILCA, G. STEFANESCU, O. BADULESCU et al., Diabetic cardiomyopathy: current approach and potential diagnostic and therapeutic targets, J ournal of Diabetes Research, volume 2017, article ID 1310265, 7 pages.

4.I. FALCAO-PIRES, A.F. LEITE-MOREIRA, Diabetic Cardiomyopathy: understanding the molecular and cellular basis to the progress in diagnosis and treatment, Heart Failure Reviews, vol. 17, no. 3, pp. 325-344, 2012.
5.P. LIBBY, P.M. RIDKER, A. MASERI. Inflammation and atherosclerosis, Circulation, vol. 105, pp. 1135-1143, 2002.

6.A.M. SCHMIDT, S.D. YAN, J .L. W AUTIER et al., Activation of receptor for advanced glycation end products: a mechanism for chronic vascular dysfunction in diabetic vasculopathy and atherosclerosis, Circulation Research, vol. 84, pp. 489-497, 1999.

7.J.W. BAYNES, S.R. THORPE, Role of oxidative stress in diabetic complications: a new perspective on an old paradigm, Diabetes, vol. 48, pp 1-9,1999.

8.MAPANGA R.F., FAADIEL ESSOP M., Damaging effects of hyperglycemia on cardiovascular function: spotlight on glucose metabolic pathways, American Journal of Physiology, vol. 310, H153H173, 2016.

9.DANGAS G.D., FARKOUH M.E., SLEEPER L.A., et al, Long-term outcome of $\mathrm{PCI}$ versus CABG in insulin and non-insulin-treated diabetic patients: results from the FREEDOM trial, J ournal of the American College of Cardiology, vol. 64, 1189-97, 2014.

10.SIRBU, P.D, TUDOR, R., VERINGA,V., CIUNTU, B.M., RADU, V., CIUBARA, B., BADULESCU, O.V., Strontium Ranelate in the Healing of Fractures Complicated with Delayed Union. It is Really Effective?, Rev.Chim.(Bucharest), 68, no. 8, 2017, p. 1825-1828.

11.SIRBU, PD; TUDOR, R; BEREA, G; SCRIPCARU, A; CIUBARA, B; BADULESCU, OV. Bipolar Polyethylene Radial Head Artroplasty in Posttraumatic Unstable Elbows. Prosthetic design and clinical results, Mat. Plast., 54, no.2, 2017, p. 298-301.

12.CHAN A.Y.W., SWAMINATHAN R., COCKRAM C.S. Effectiveness of sodium fluoride as a preservative of glucose in blood, Clinical Chemistry, vol. 35, 315-317, 1989.

13.MARFELLA R., SINISCALCHI M., ESPOSITO K., et al, Effects of stress hyperglycemia on acute myocardial infarction: role of inflammatory immune process in functional cardiac outcome, Diabetes Care, vol. 26, 3129-3135, 2003.

14.DEEDWANIA P., KOSIBOROD M., BARRETT E., et al., Hyperglycemia and acute coronary syndromes, Circulation, vol. 117, 1610-1619, 2008. 15.MCMILLIN J.M., BLOOD GLUCOSE, Clinical Methods: the history, physical, and laboratory examinations, 3ed Edition, chapter 45, 1230, 1990, ISBN-10: 0-409-90077-X.

Manuscript received: 21.01.2019 